\title{
Erratum to: Febrile response induced by cecal ligation and puncture (CLP) in rats: involvement of prostaglandin $E_{2}$ and cytokines
}

\author{
Maria José Figueiredo - Denis Melo Soares - Juliano Manvailer Martins • \\ Renes de Resende Machado • Carlos Arterio Sorgi • Lucia Helena Faccioli • \\ Miriam Cristina Contin de Melo • David do Carmo Malvar • Glória E. P. Souza
}

Published online: 23 June 2012

(c) Springer-Verlag 2012

Erratum to: Med Microbiol Immunol (2012)

201:219-229

DOI 10.1007/s00430-011-0225-y

In the original publication, the first and last names of second, fourth, and seventh authors were published incorrectly. For the second author, the first name is Denis Melo and the last name is Soares. For the fourth author, the first name is Renes de Resende and the last name is Machado. For the seventh author, the first name is Miriam Cristina Contin de and the last name is Melo.

The online version of the original article can be found under doi:10.1007/s00430-011-0225-y.

M. J. Figueiredo $(\bowtie) \cdot$ D. M. Soares .

J. M. Martins - R. d. R. Machado - M. C. C. d. Melo .

D. d. C. Malvar - G. E. P. Souza

Laboratory of Pharmacology, Department of Physic

and Chemistry, Faculty of Pharmaceutical Sciences,

University of São Paulo, Av. do Café, s/n, Campus Universitário,

14049-903 Ribeirão Preto, São Paulo, Brazil

e-mail: zzfigueiredo@usp.br

Present Address:

D. M. Soares

Lab of Pharmacology, Department of Medicament,

Faculty of Pharmacy, UFBA, Salvador, BA, Brazil

C. A. Sorgi - L. H. Faccioli

Department of Clinical Analysis, Toxicology and Bromatology,

Faculty of Pharmaceutical Sciences, University of São Paulo,

Av. do café, s/n, 14049-903 Ribeirão Preto, São Paulo, Brazil 